\title{
A Case Study for the Welding of Dissimilar EN AW 6082 and EN AW 5083 Aluminum Alloys by Friction Stir Welding
}

\author{
Sefika Kasman $^{1, *}$, Fatih Kahraman ${ }^{2}$, Anıl Emiralioğlu ${ }^{2,3}$ and Haydar Kahraman 3,4 \\ 1 Izmir Vocational School, Dokuz Eylul University, Izmir 35160, Turkey \\ 2 Department of Mechanical Engineering, Faculty of Engineering, Dokuz Eylul University, Izmir 35140, \\ Turkey; fatih.kahraman@deu.edu.tr (F.K.); anilemiralioglu@gmail.com (A.E.) \\ 3 Graduate School of Natural and Applied Sciences, Dokuz Eylul University, Izmir 35140, Turkey; \\ haydar.kahraman@deu.edu.tr \\ 4 Department of MetallurgicalandMaterialsEngineering, Faculty of Engineering, Dokuz Eylul University, \\ Izmir 35140, Turkey \\ * Correspondence: sefika.kasman@deu.edu.tr; Tel.: +90-533-731-4673
}

Academic Editors: Halil Ibrahim Kurt, Adem Kurt and Necip Fazil Yilmaz

Received: 10 November 2016; Accepted: 23 December 2016; Published: 29 December 2016

\begin{abstract}
The aim of this study is to investigate the effect of keeping constant the tool rotational speed to the welding speed ratio ( $v$ ratio) on the mechanical properties of the dissimilar friction stir welding of EN AW6082-T6 and EN AW5083-H111. Two different pins shaped as triangular and pentagonal were associated with the constant $v$ ratio. From the tensile test results, it was found that the $v$ ratio does not create an evident change in the weld joint strength. The small cavity- and tunnel-type defects were observed at the nugget zone and located on the advancing side of the pin. These defects caused a decrease in the strength and elongation of the weld joint. The most important inference obtained from the experimental results is that if the $v$ ratio is kept constant, the weld joint strength for each weld does not correspond to a constant value.
\end{abstract}

Keywords: dissimilar friction stir welding; pin shape; mechanical properties

\section{Introduction}

It is well known that aluminum alloys have inherent and versatility properties such as resistance to corrosion, good formability, a good strength to weight ratio, low density and electrical and thermal conductivity. These properties make it a high-demand material compared to the steel alloys in industrial application, particularly in the automotive, shipbuilding, packaging, construction and architecture fields, etc. With the growth of demand for aluminum alloys in a wide variety of applications, the welding and manufacturing process of aluminum alloys requires special knowledge and experiences. The welding of aluminum alloys by fusion welding techniques produces some defects such as pores, loss of some elements, hot cracking, stress corrosion cracking, and mismatch between the filler alloy and the workpiece material in dissimilar welding, causing the loss of strength of the weld joint [1]. To overcome these problems, the solid-state welding techniques are the best alternatives for the welding of aluminum alloys.

Aluminum-magnesium alloys are non-heat-treatable alloys which provide good mechanical properties, corrosion resistance, and good workability and weldability. These excellent properties make it an attractive material in a wide range of construction and structural applications in the automotive and shipbuilding industries. Aluminum alloy EN AW5083 is one of the aluminum-magnesium alloys and it has high mechanical strength and fusion weldability [2]. The aluminum-magnesium-silicon 
alloys are heat-treatable alloys and have a medium strength with excellent corrosion resistance. These alloys are being used in automotive parts, especially in body sheets to decrease their weight. EN AW6082 alloy is one of the aluminum-magnesium-silicon alloys and it has very good weldability, but its strength is lowered in the weld zone [3]. Many studies have focused on the friction stir welding (FSW) process of aluminum alloys and it is well known that some of aluminum alloys cannot be welded by the fusion welding process. Therefore, in order to achieve more information about the FSW process, critical factors such as the tool design, rotational speed and welding speed have been subjected to investigation. There are many studies related to the FSW of EN AW5083 and EN AW6082, but the dissimilar FS welding of these alloys is limited. Also, in most of the studies, the tool pin shape is a straight, cylindrical threaded profile. There are some studies in the literature on dissimilar FS welding of EN AW6082 and EN AW5083. Peel et al. [4] performed studies to determine the effect of the tool rotational and welding speed on the microstructure of welding zones and weld properties of dissimilar FSW EN AW5083-EN AW6082 joints. Donatus et al. [5] focused on identifying corrosion-susceptible regions of dissimilar friction stir welds of EN AW5083-O and EN AW6082-T6. Donatus et al. [6] performed dissimilar FSW studies on EN AW5083-O and EN AW6082-T6 to investigate the material flow in the friction stir welds. Steuwer et al. [7] investigated the effect of the welding parameters on the residual stress profiles on the same welds. Apart from these studies, Leitão et al. [8] conducted two-stage experimental studies in order to determine the effect of FSW parameters on each material and the weldability of dissimilar alloys at high temperature. Sun et al. [9] studied the dissimilar friction stir welding of ultrafine-grained 1050 and 6061-T6 aluminum alloys to understand joint characterization. Aval et al. [10] investigated the thermo-mechanical behavior and microstructural events of dissimilar FSW of AA6061-T6 and AA5086-O.

The present study is focused on the effect of tool geometry and the ratio of the tool rotational speed to the welding speed ( $v$ ratio) on the mechanical and macrostructural properties of dissimilar FSW of EN AW6082-T6 and EN AW5083-H111 alloys.

\section{Friction Stir Welding}

Friction stir welding is the alternative welding technique for some aluminum alloys that cannot be welded by the fusion welding techniques. The major difference is that FSW occurs below the melting point and it is located in the welding group occurring in the solid-state phase. The principles of the FSW process are that a tool consisting of a shoulder and a pin plunges into the butted surface of the plates and then the rotational and translational movement perform the welding process. The necessary heat for welding is provided by the tool shoulder and pin, the speed of the tool rotation and the movement. The friction between the tool pin and the workpiece generates the heat and, therefore, the pin shape has a particular effect and an increase in the tool rotational speed increases the heat. Also, the heat decreases with the increase in the tool movement speed or welding speed. In this context, a mathematical approximation is developed as in Equation (1) [11,12].

$$
Q=(\alpha q) / W=4 / 3 \pi^{2}\left(\alpha \mu P . T R S . R^{3}\right) / W S=\beta . T R S / W S
$$

where $Q$ is the heat input per unit length, $\alpha$ is the heat input efficiency, WS is the welding speed, and TRS is the tool rotational speed. For a welding condition, $\alpha, \mu, P, R$ and $\beta$ are the constant values. It is understood from Equation (1) that the tool rotational speed and the welding speed are the main factors for determining the per unit heat input. By the effect of the generated heat, the material around the pin flows from the front to the back of the tool and a deformation occurs from the tool movement. Then, the weld joint is completed by repeating this cycle.

\section{Materials and Methods}

Aluminum alloys EN AW5083-H111 and EN AW6082-T6 plates with a thickness of $5 \mathrm{~mm}$, width of $150 \mathrm{~mm}$ and a length of $200 \mathrm{~mm}$ were used as the weld plates. The chemical composition 
and the mechanical properties of the plate materials were given at Tables 1 and 2, respectively. Before welding experiments, the butted surfaces of plates were cleaned from dust and any residue.

Table 1. The chemical composition of aluminum alloys used in the present study (wt. \%).

\begin{tabular}{cccccccccc}
\hline Alloy/Elements & $\mathbf{C u}$ & $\mathbf{S i}$ & $\mathbf{M g}$ & $\mathbf{M n}$ & $\mathbf{Z n}$ & $\mathbf{T i}$ & $\mathbf{C r}$ & $\mathbf{F e}$ & $\mathbf{A 1}$ \\
\hline EN AW6082-T6 & 0.23 & 0.98 & 1.02 & 0.6 & 0.21 & 0.01 & 0.03 & 0.6 & Bal. \\
EN AW5083-H111 & 0.056 & 0.093 & 4.19 & 0.53 & 0.09 & 0.007 & 0.083 & 0.243 & Bal. \\
\hline
\end{tabular}

Table 2. Mechanical properties of aluminum alloys.

\begin{tabular}{ccc}
\hline Alloy & Ultimate Tensile Strength (MPa) & Elongation (\%) \\
\hline EN AW6082-T6 & 293.21 & 8.12 \\
EN AW5083-H111 & 325 & 17.6 \\
\hline
\end{tabular}

The dissimilar FSW were performed with a universal milling machine (Russia). For the welding experiments, a backing plate was used to place and clamp the plates. A schematic FSW experiment and components was shown in Figure 1. The welding direction was set as the parallel to the rolling direction of plates and the tool was tilted at the $2^{\circ}$ to the normal direction of the plates. A sample figure for FSW experiments was given in Figure 1. The welding tool was made of DIN EN 1.7131 steel and geometrically shaped as a triangular and pentagonal shown in Figure 2. The tool properties were listed in Table 3. With the aim of analyzing the effect of the constant ratio of the tool rotational speed to the welding speed " $v$ " (TRS (rpm)/WS $\left(\mathrm{mm} \cdot \mathrm{min}^{-1}\right)$ ), an experimental layout was conducted given at Table 4. As shown in Table 4, the $v$ ratio was kept fixed at 10.

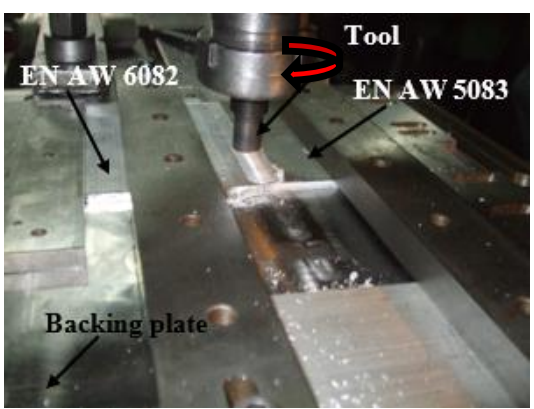

Figure 1. A sample for FSW experiment.

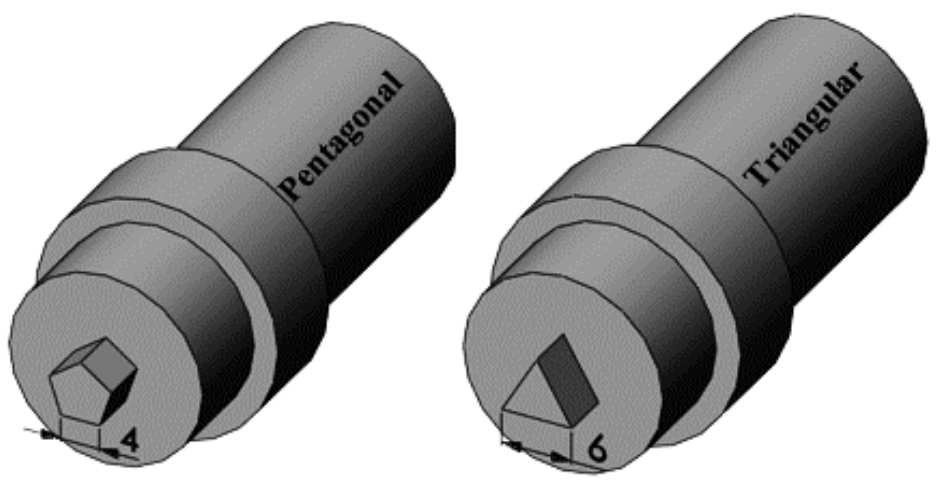

Figure 2. The tool pin profiles used in the FSW experiment.

The macrostructural analyses were performed on the cross sectioned perpendicular to the weld direction. Each sample was subjected to the standard grinding and etching process. The etching is 
performed by the modified Keller solution. Following the surface preparations, the optical macroscopic analyses were done.

A joint fabricated by the FSW process was characterized with the ultimate tensile strength (UTS, MPa) and percentage of elongation $(\varepsilon, \%)$. The tensile tests were carried out on $500 \mathrm{kN}$ hydraulic testing machine (Shimadzu, Kyoto, Japan) with a cross-head speed of $2 \mathrm{~mm} \cdot \mathrm{min}^{-1}$. The samples were prepared according to the ASTM E8-M. At least two samples were tested and the average of those tests was used in the final decision and analyses.

Table 3. FSW process parameters and their levels.

\begin{tabular}{|c|c|c|c|c|c|}
\hline Parameters (Unit) & Symbol & & & evels & \\
\hline Tool Rotational Speed (rpm) & TRS & 400 & 500 & 630 & 800 \\
\hline Welding Speed $\left(\mathrm{mm} \cdot \mathrm{min}^{-1}\right)$ & WS & 40 & 50 & 63 & 80 \\
\hline Tool Rotational Speed-to-Welding Speed & $v$ & & & 10 & \\
\hline Pin shape & PS & & $\mathrm{T}$ & & $\mathrm{P}$ \\
\hline \multicolumn{6}{|c|}{ Fixed parameters } \\
\hline Tool shoulder diameter (mm) & $D$ & & & 20 & \\
\hline Tool tilt angle $\left(^{\circ}\right)$ & $\alpha$ & & & 2 & \\
\hline Dwell time (s) & $t$ & & & 20 & \\
\hline
\end{tabular}

Table 4. FSW experimental layout with responses (UTS, $\varepsilon$, \%).

\begin{tabular}{|c|c|c|c|c|c|c|c|c|c|}
\hline \multirow{3}{*}{ Exp. No. } & \multicolumn{4}{|c|}{ Process Parameters } & \multicolumn{5}{|c|}{ Welding Performance } \\
\hline & \multirow{2}{*}{ PS } & \multirow{2}{*}{ TRS } & \multirow{2}{*}{ WS } & \multirow{2}{*}{$\frac{v}{\text { TRS/WS }}$} & \multirow{2}{*}{ UTS (MPa) } & \multirow{2}{*}{$\varepsilon(\%)$} & \multicolumn{2}{|c|}{ Efficiency } & \multirow{2}{*}{ Defect } \\
\hline & & & & & & & 6082 & 5083 & \\
\hline 1 & $\mathrm{~T}$ & 400 & 40 & \multirow{8}{*}{10} & 164.36 & 0.49 & 56.06 & 50.57 & Defective \\
\hline 2 & $\mathrm{~T}$ & 500 & 50 & & 188.68 & 4.6 & 64.35 & 58.06 & Defective \\
\hline 3 & $\mathrm{~T}$ & 630 & 63 & & 198 & 4.7 & 67.53 & 60.92 & Defective \\
\hline 4 & $\mathrm{~T}$ & 800 & 80 & & 198.48 & 4.26 & 67.69 & 61.07 & Sound weld \\
\hline 5 & $\mathrm{P}$ & 400 & 40 & & 180.59 & 4.14 & 61.59 & 55.57 & Defective \\
\hline 6 & $\mathrm{P}$ & 500 & 50 & & 192.27 & 4.312 & 65.57 & 59.16 & Defective \\
\hline 7 & $\mathrm{P}$ & 630 & 63 & & 181.96 & 0.39 & 62.06 & 55.99 & Defective \\
\hline 8 & $\mathrm{P}$ & 800 & 80 & & 187.85 & 4.24 & 64.07 & 57.80 & Defective \\
\hline
\end{tabular}

\section{Results and Discussion}

The present study focused on the effect of fixing the ratio of the tool rotational speed to the welding speed " $v$ " on the microstructure and mechanical properties of dissimilar FS welding of EN AW6082 to EN AW5083. In total, eight FSW experiments were performed and the results were evaluated as below.

\subsection{Macrostructure and Microstructure Investigations}

A weld joint is characterized by three distinct zones and a sample is shown in the Figure 3. The zones are affected by the tool rotational speed, welding speed and tool pin shape. The investigation of the macrostructure for each weld joint in the context of the present study was performed on the cross-section of the weld joints shown in Figure 3. As shown in Figure 3, the shape of nugget zone (NZ) and thermomechanically affected zone (TMAZ) is highly affected from the FSW parameters and pin shape. The pin shape shows the predominant effect on the NZ shape compared to the $v$ ratio. The onion ring-type structure was detected all in the NZ. The visibility of onion rings in the NZ produced by a pentagonal-shaped pin is more distinctive and the wideness of NZ is higher compared to the triangular-shaped pin. The reason could be the dimension of the circumference of the pin. The flow of deformed and elongated grains in the TMAZ is affected from the tool pin shape and 
generated heat. The width of the TMAZ is bigger at the condition of Exp. 3,4,7,8. It is attributed to the higher heat input. As seen in Equation (1), an increase in TRS increases the heat input due to higher frictional heat [12] and this causes an increase in width of the TMAZ. Exp. 3,4,7,8 were performed with a higher TRS.

Figure 4 shows a sample microstructure taken from the weld joint of Exp. 6 and 8. The regions and borders of the welded metals can be clearly detected due to different etching behavior. The flow of the material in the nugget zone shows differences according to the value of TRS and WS. The shape of the onion rings is similar for the entire weld joint and almost has an elliptical form. When the onion ring is sectioned as vertical, it is seen that a part of the onion ring closer to the joint root is composed from EN AW6082. The reason is due to the rotation of the tool and the placement of EN AW6082. An onion ring is composed of a dark and a bright ring. These rings grow outward from the center and are placed in the nugget zone as they are ordered consecutively. The composition of the onion rings depends on the tool rotational speed. The welding speed determines the rotation times of the tool per minute. The material forged by the tool and is moved from one side to the other side which is repeated many times by the effect of tool rotational speed. This effect causes the forming of onion rings.

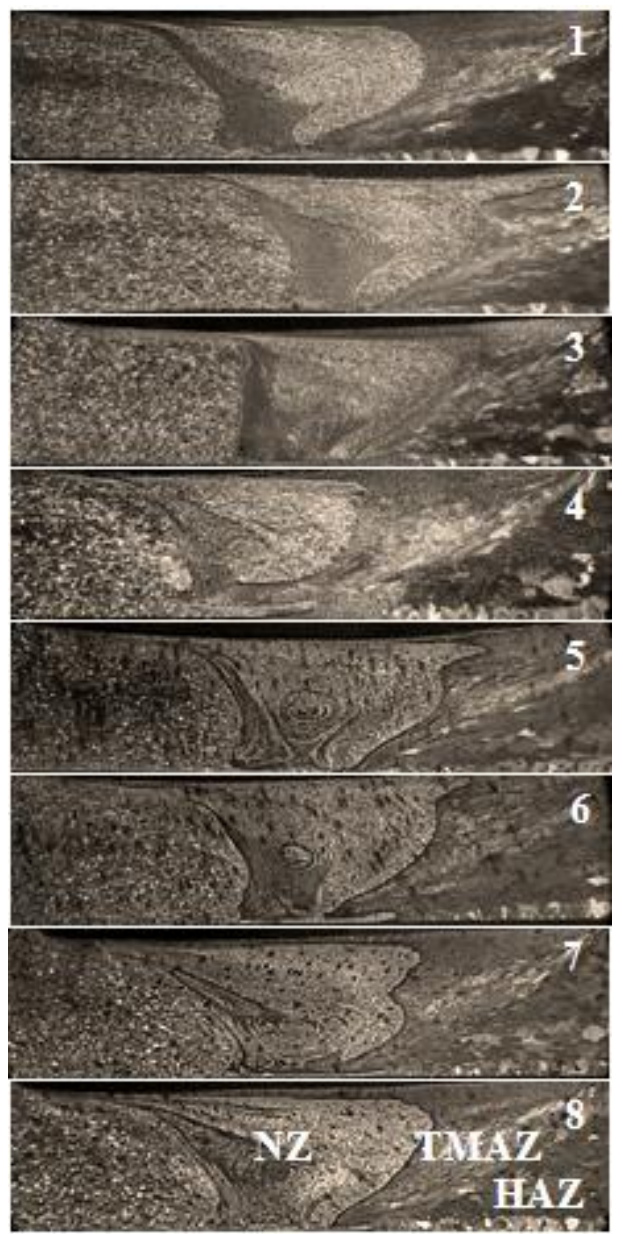

Figure 3. Cross-section of each weld joint.

Two defective welds shown in Figure 5 were taken from the joint fabricated by the triangular-shaped pin at the TRSs of 400 and $500 \mathrm{rpm}$ and WSs of 40 and $50 \mathrm{~mm} \cdot \mathrm{min}^{-1}$. Tunnel- and cavity-type defects were clearly detected from the weld joint and similar defects were also observed at the other joints. The defects were located at the side of the pin tip and EN AW6082. There is more than one small defect and these caused a decrease in the mechanical properties of the 
weld joints. The reason of formed defects is the amount of heat input; in some cases, a higher or insufficient heat input produced defects, and especially insufficient heat input resulted in inadequate material flow which led to tunnel- or cavity-like defects. In the present study, the small clustered defects at the root of weld joint were clearly observed and appeared at both the advancing and retracting side. The possible reason for these defects is insufficient heat input.

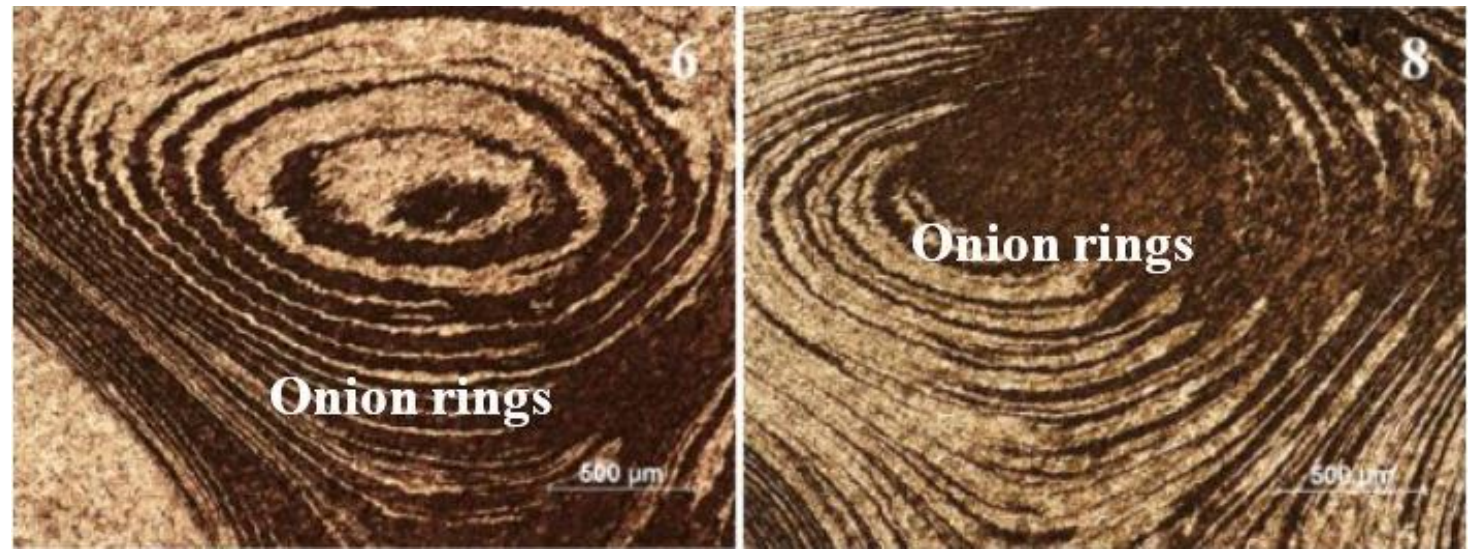

Figure 4. Nugget zone structures consisting of onion rings.
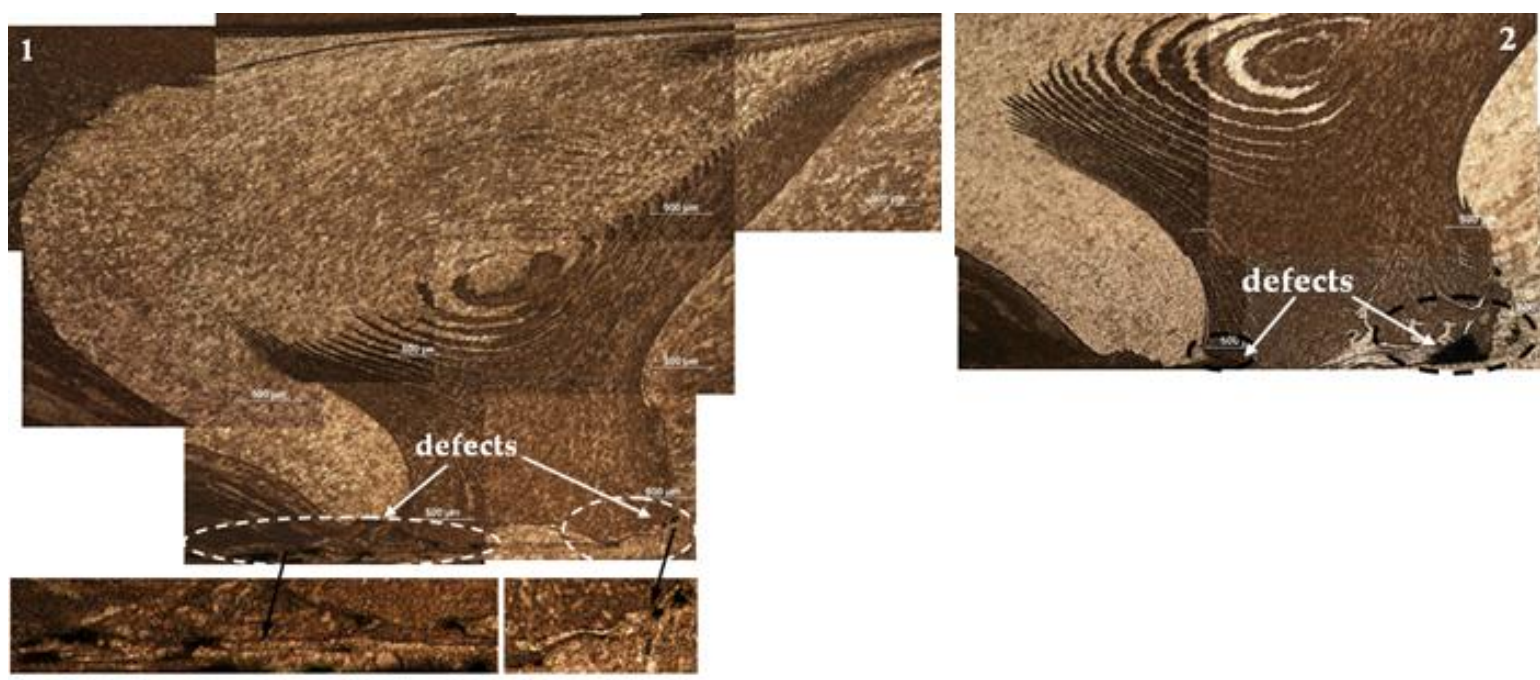

Figure 5. Samples for defective weld joints (Exp. 1 and Exp. 2).

\subsection{Mechanical Properties}

In order to determine the mechanical properties of each weld joint, the tensile tests were conducted and the results were associated with the process parameters. The ultimate tensile strength (UTS) and percentage of elongation $(\varepsilon, \%)$ were considered as the process responses. The tensile test results were given in Table 4 and Figures 6 and 7. Also, the fracture location of each weld joint is shown in Figure 8. As shown in Figure 8, except the welding of Exp. 1 and Exp. 7, the fracture of the joints was located at the heat affected zone (HAZ) and the side of EN AW6082. The fracture for the welding of Exp. 1 and Exp. 7 was located at the nugget zone. As mentioned before, except Exp. 4, all the weld joints contained many small defects such as cavities and some of the joints as in Exp. 2 had a tunnel-type defect. From Figure 6, the effects of the defects on the UTS can be clearly seen and all the UTS values are lower than those of the base materials. The UTS value for the triangular-shaped pin increased with the increase of the tool rotational speed independent of the welding speed. However, this tendency 
was not observed for the pentagonal-shaped pin. The UTS for Exp. 1 was the lowest (164.36 MPa) one of all in the weld joint and it corresponded to 56.06\% efficiency for EN AW6082. The $\varepsilon$ value in Figure 7 was verified by the UTS result. The value of $\varepsilon$ was 0.49 and, also, the fracture location of this joint was at the $\mathrm{NZ}$ and we observed that there was no significant elongation compared with the other joints. A similar result was observed at the welding of $630 \mathrm{rpm}$ and $63 \mathrm{~mm} \cdot \mathrm{min}^{-1}$ (Exp. 7) produced by the pentagonal-shaped pin. The fracture location was also at the NZ. According to the UTS results, the welding with the highest strength was performed at the condition of $800 \mathrm{rpm}$ and $80 \mathrm{~mm} \cdot \mathrm{min}^{-1}$ by the triangular-shaped pin, and an important issue was observed relating to the UTS values for both of Exp. 3 and Exp. 4: the results are almost the same. The difference between the two UTS values is small enough to be ignored. It can be taken as an important inference for the strength and the elongation of the welded samples; the results are smaller than the base metals' UTS and $\varepsilon$. The welding efficiency was determined by comparing the UTS values for all the weld joints with the base metals. The results were listed in Table 4. It is obvious that the lowest efficiency was obtained from the defective weld joints. The efficiency for joint strength ranged from $55 \%$ to $68 \%$. As an association between the UTSs of weld joints and UTSs of base materials, a result was reached: defects cause the decrease of the UTS and $\varepsilon$ of FSW samples compared to those of base materials.

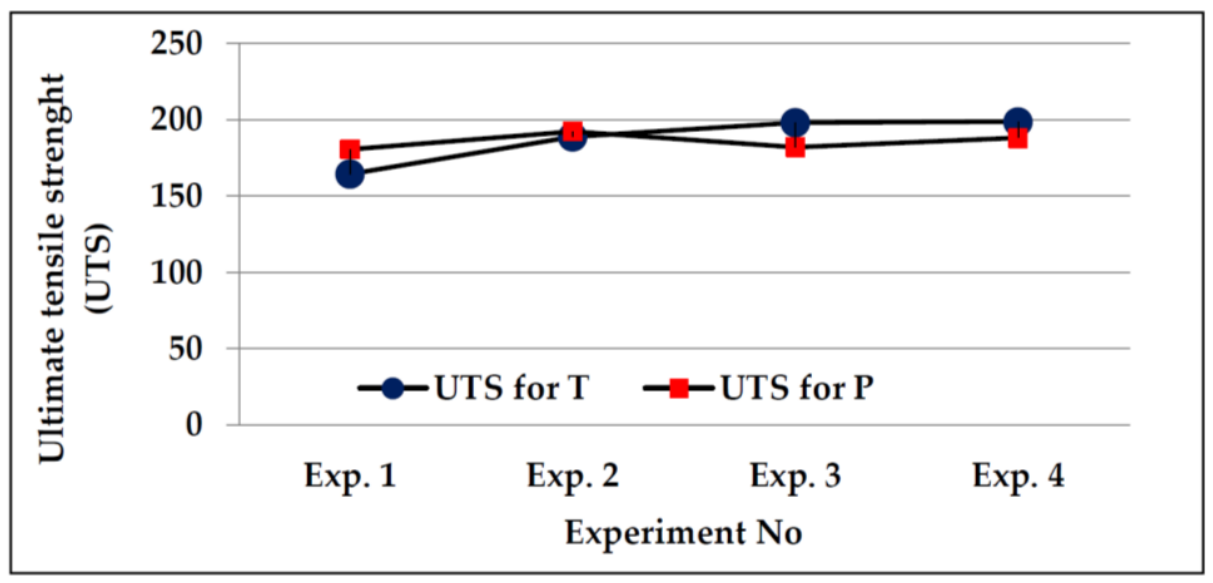

Figure 6. The comparative UTS results for both tool pins.

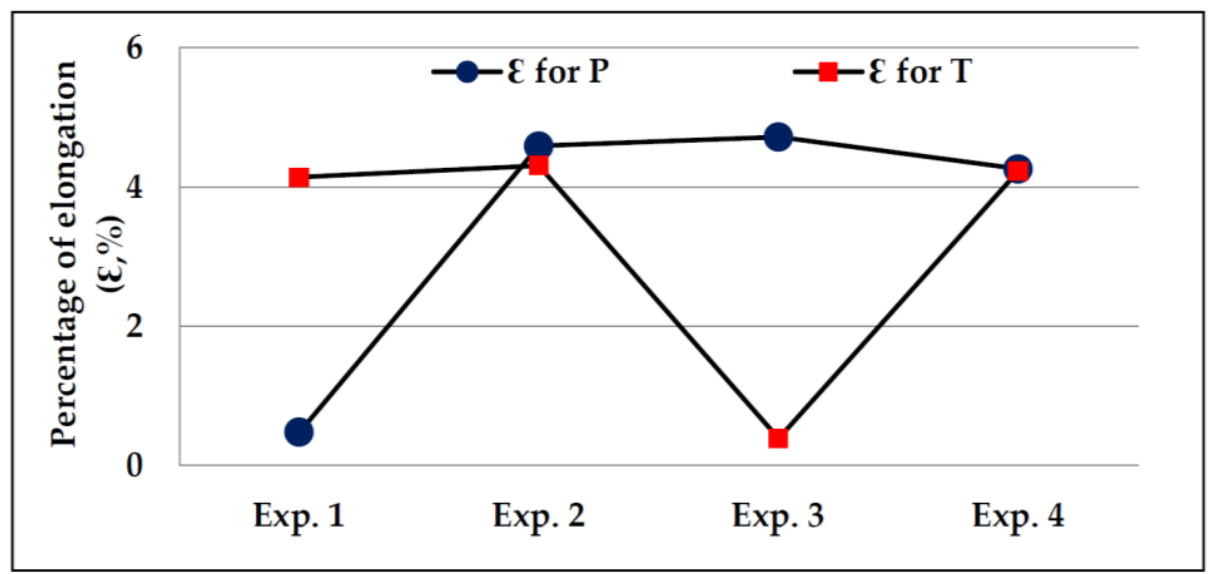

Figure 7. The comparative $\varepsilon$ results for both tool pins. 


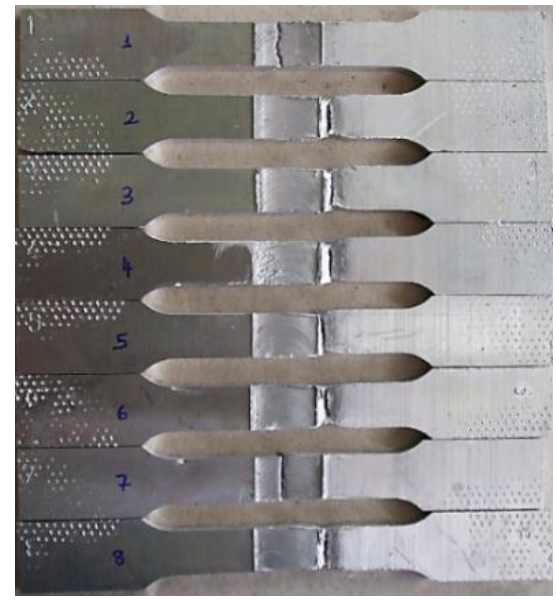

Figure 8. The fracture location of weld samples after tensile tests.

\section{Conclusions}

The present study focused on the effect of the ratio of the tool rotation speed to the welding speed $(v$ ratio) on the tensile properties and macrostructural alteration for dissimilar friction stir welding of EN AW6082 to EN AW5083 aluminum alloys. Two different pin shapes were associated with a constant $v$ ratio. The following conclusions were drawn.

- The pin shape has a significant effect on the tensile properties and microstructure. The strengths of the weld joint fabricated by the pentagonal-shaped pin was smaller than those of triangular-shaped pin for Exp. 7 and Exp. 8.

- The highest tensile strength was obtained from the weld joint fabricated with a triangular-shaped pin and the UTS and $\varepsilon$ values were $198.48 \mathrm{MPa}$ and $4.26 \%$, respectively.

- The efficiency for joint strength is ranged from $55 \%$ to $68 \%$. The variation trend changes depending on both defects in the weld joint and the strength of the base material.

- Except for the fourth weld joint, the others contained small cavity and tunnel defects.

- The fracture of each joint except in Exp. 1 and Exp. 7 was located at the side of EN AW6082.

- The nugget zone profile was affected by the pin shape. The nugget zone of each weld contained onion rings. The shape of the onion rings was dependent on the value of the tool rotational speed and welding speed.

- The effect of a constant $v$ ratio on the profile and structure of the nugget zone is dependent on both the welding speed and tool rotational speed.

- At a lower tool rotational speed and welding speed for each tool pin shape, lower UTS values were obtained. The UTS increased as the tool rotational speed and the welding speed increased, while keeping the $v$ ratio constant for the triangular-shaped pin.

Acknowledgments: The present study is supported by a scientific project research (No. 2011.KB.FEN.045).

Author Contributions: Sefika Kasman and Fatih Kahraman designed the experiments; Anıl Emiralioglu and Haydar Kahraman performed the experiments with Sefika Kasman and Fatih Kahraman; all authors analyzed the data and contributed to written of paper.

Conflicts of Interest: The authors declare no conflict of interest.

\section{References}

1. DebRoy, T.; Bhadeshia, H.K.D.H. Friction stir welding of dissimilar alloys-A perspective. Sci. Technol. Weld. Join. 2010, 15, 266-270. [CrossRef] 
2. Aalco Metal Limited, Aluminium Alloys. Available online: www.aalco.co.uk/datasheets/Aalco-MetalsLtd_Aluminium-Alloy-5083--0-H111-Sheet-and-Plate_149.pdf.ashx (accessed on 9 November 2016).

3. Aalco Metal Limited, Aluminium Alloys. Available online: www.aalco.co.uk/datasheets/Aalco-MetalsLtd_Aluminium-Alloy-6082-T6T651-Plate_148.pdf.ashx (accessed on 9 November 2016).

4. Peel, M.J.; Steuwer, A.; Withers, P.J. Dissimilar Friction Stir Welds in EN AW5083-EN AW6082, Part II: Process Parameter Effects on Microstructure. Metall. Mater. Trans. A 2006, 37, 2195-2206. [CrossRef]

5. Donatus, U.; Thompson, G.E.; Zhou, X.; Wang, J.; Cassell, A.; Beamish, K. Corrosion susceptibility of dissimilar friction stir welds of EN AW5083 and EN AW6082 alloys. Mater. Charact. 2015, 107, 85-97. [CrossRef]

6. Donatus, U.; Thompson, G.E.; Zhou, X.; Wang, J.; Beamish, K. Flow patterns in friction stir welds of EN AW5083 and EN AW6082 alloys. Mater. Des. 2015, 83, 203-213.

7. Steuwer, A.; Peel, M.J.; Withers, P.J. Dissimilar friction stir welds in EN AW5083-EN AW6082: The effect of process parameters on residual stress. Mater. Sci. Eng. A 2006, 441, 187-196. [CrossRef]

8. Leitão, C.; Louro, R.; Rodrigues, D.M. Analysis of high temperature plastic behaviour and its relation with weldability in friction stir welding for aluminium alloys AA5083-H111 and AA6082-T6. Mater. Des. 2012, 37, 402-409. [CrossRef]

9. Sun, Y.; Tsuji, N.; Fujii, H. Microstructure and mechanical properties of dissimilar friction stir welding between ultrafine grained 1050 and 6061-t6 aluminum alloys. Metals 2016, 6, 249. [CrossRef]

10. Aval, H.J.; Serajzadeh, S.; Kokabi, A.H. Thermo-mechanical and microstructural issues in dissimilar friction stir welding of AA5086-AA6061. J. Mater. Sci. 2011, 46, 3258-3268. [CrossRef]

11. Hao, H.L.; Ni, D.R.; Huang, H.; Wang, D.; Xiao, B.L.; Nie, Z.R.; Ma, Z.Y. Effect of welding parameters on microstructure and mechanical properties of friction stir welded Al-Mg-Er alloy. Mater. Sci. Eng. A 2013, 559, 889-896. [CrossRef]

12. Mishra, R.S.; Ma, Z.Y. Friction stir welding and processing. Mater. Sci. Eng. R 2005, 50, 1-78. [CrossRef]

(C) 2016 by the authors; licensee MDPI, Basel, Switzerland. This article is an open access article distributed under the terms and conditions of the Creative Commons Attribution (CC-BY) license (http://creativecommons.org/licenses/by/4.0/). 